\title{
Research on Supplementary Responsibility in China's Tort Liability Law
}

\author{
Yuanxuan Hou \\ Tianjin University, Tianjin, 300072
}

Keywords: Supplementary Responsibility, China's Tort Liability Law

\begin{abstract}
China's Tort Liability Law stipulates the supplementary responsibility of the security guarantee obligor in the case of third party infringement, and the supplementary responsibility of the school and other educational institutions when the third party infringes in the campus accident. The new type of supplementary liability in tort liability is undoubtedly a major innovation in the field of tort law in China. The establishment of the supplementary liability system can not only solve the legal dilemma faced by the joint liability and the liability according to the third party's infringement, but also embody the fair principle of the civil law, and at the same time exert the social function of the law to promote social harmony and stability.
\end{abstract}

\section{Introduction}

The infringement supplement liability system applies to the combination of direct infringement by a third party and inaction by a responsible person. The legal relationship in this case is relatively complicated, and the current legislation in China is not clear enough about the system. The disputes in the academic circles are constant, and there are many doubts in the application of supplementary responsibilities.

Different from the judicial interpretation mentioned above, the Tort Liability Law only stipulates several types of behaviors that supplement liability, and it does not stipulate the right of recovery of the responsible person. Moreover, the provisions on the article are relatively simple, and there is no sound legal system for infringement supplementary liability system. Today, as the pace of social life continues to accelerate, various types of infringement supplementary liability cases are increasing, and existing legal provisions are difficult to provide a strong legal basis for the handling of similar cases. At the same time, the current academic disputes on the design of infringement supplemental liability system have not been interrupted, such as the scope of application of infringement supplementary liability, the scope of responsibility of the supplementary responsible person, and whether the supplementary responsible person has the right to recover after the responsibility. If the disputes in these theoretical views are not consistent, the process of perfecting the infringement supplemental liability system will be slow, and the difficulties in practical operations will be difficult to solve effectively.

\section{The Concept of Infringement Supplementary Liability}

The concept of infringement supplementary liability is not defined in the legislation, and the academic circles are also inconsistent. Professor Wei Zhenduo believes that supplementary liability refers to the responsibility of the relevant person to supplement the compensation only for the insufficient part when the responsible person cannot fully bear the civil liability that he should bear. Professor Zhang Xinbao believes that in cases where the damage is caused by an infringement and triggers two mutually overlapping claims, if the law requires the victim to exercise the claim for compensation, it must be in the order in which the victim must first ask for The former responsible person assumes responsibility and can only ask the responsible person in the latter position to compensate if his property is insufficient to fully compensate the victim. At this time, the responsibility of the responsible person in the latter position is the supplementary liability for infringement. Professor Yang Lixin believes that the supplementary liability for infringement is the form of tort liability in which the actor of the index bears full liability for the same damage 
according to different reasons, and the responsibility of all responsible persons is eliminated due to the performance of a responsible person. Professor Huang Long believes that according to the law or the parties, two civil liabilities with primary or secondary points or primary and secondary relationships for the same damage are obtained, and the secondary responsibility is less than the primary responsibility and has a supplementary relationship and implicated relationship with the primary responsibility. It is a supplementary responsibility.

Looking at the above-mentioned concepts of several kinds of infringement supplementary liability, we cannot accurately define the core attributes of supplementary liability, or are too abstract, or only emphasize the characteristics of complementary responsibility, or the inaccurate positioning of the nature of supplementary responsibility, or supplement The reasons for the occurrence of the responsibility are incorrectly explained. The author believes that the definition of the concept of infringement supplementary liability should clarify its application and core characteristics, and make the concept open, not just for a specific case. The so-called infringement supplementary liability means that the perpetrator of the obligation has caused all the damages caused by the infringement of the direct perpetrator (third party) because of the negligence of the perpetrator, and when the direct perpetrator is unknown or cannot fully bear the liability for damages, It is the responsibility of the actor who has the obligation to bear the corresponding supplementary compensation for the insufficient part and can recover the compensation from the direct victim after the compensation.

\section{Characteristics of Infringement Supplementary Liability}

First, the infringement supplemental liability is sequential. This sequence of characteristics corresponds to the meaning of the term "supplementary" in the infringement supplementary liability and is the requirement of the infringement supplementary liability. The premise of supplementary liability is that the victim receives insufficient compensation. Of course, to determine whether such "deficiency" exists, the victim needs to be determined from the amount of compensation obtained by the person directly responsible, so this requires the victim to follow the claim.

Second, the infringement supplemental liability is both independent and implicated. The reason why the infringement supplementary liability is independent is that the liability of the supplementary responsible person is different from the direct infringement liability of the third party, and it is not absorbed by the direct responsibility. When the victim does not receive full compensation at the immediate responsible person, he can directly claim the right to the supplementary responsible person. The reason why it is implicated is that it is ultimately the result of damage caused by the active harm of the directly responsible person, resulting in the burden of supplementary responsibility. Moreover, the burden of supplementary liability and the size of its share are affected by the responsibility of the person directly responsible. In addition, to some extent, the concept of supplementary responsibility corresponds to direct responsibility, and its "supplement" is complementary to direct responsibility. Therefore, without the concept of direct responsibility, the concept of supplementary responsibility has no meaning.

Third, in the supplementary liability for infringement, the share of responsibility of the supplementary responsible person is uncertain. The supplementary responsible person did not carry out the act of positively injuring, so he was not obliged to bear the liability for the total damage of the victim, even if the victim was completely unable to obtain compensation from the person directly responsible. This can also be reflected in the term "supplementary" of supplementary responsibility. The supplementary responsible person bears the "corresponding" share, and the main consideration for determining the "corresponding" share is to supplement the responsible person's own fault. The determination of the size of the fault does not have specific quantitative criteria in the operation, resulting in uncertainty of the share of supplementary liability.

Fourth, in the supplementary liability for infringement, the supplementary responsible person has the right to recover. The right to recover here means that after the responsible person has assumed the liability for compensation within the scope of his fault, the victim has the right to claim compensation from the person directly responsible for the act of injuring the person to compensate 
for the compensation. The loss of responsibility has restored my property to the state before the responsibility. The reason why the supplementary responsible person has the right to recover is because the direct cause of the actor's responsibility is to actively infringe the perpetrator's infringement, and the perpetrator should bear the ultimate responsibility. Giving the responsible person the right to recover is the embodiment of the principle of fault liability and the inherent requirement of the system of liability for infringement.

\section{The Value Analysis of Supplementary Responsibility}

In real life, there are often cases where the injurer's whereabouts are unknown or the injurer's own inability to compensate the victim. In this case, the victim cannot receive timely and adequate relief, leading to social injustice. At the same time, in many cases of infringement, there is a type of responsible subject. Although they do not directly commit infringements, they do not fulfill their obligations, which increase the probability of causing damage. Therefore, the infringement must also occur or infringe. The occurrence of damage results is a certain responsibility. When the victim does not receive timely or complete remedies from the direct infringer, such responsible entity is required to provide compensation for the victim's loss to the extent of his fault. This makes up for the gap that the victim is unable to obtain compensation because the whereabouts of the perpetrator is unknown or unable to compensate, and also allows other responsible persons to assume corresponding responsibilities for their fault. Relief for victims is the original intention of establishing a system of supplementary liability and its primary value.

Traditional civil law does not require non-infringers to bear tort liability. However, with the continuous expansion of social interactions, the resulting civil relations are increasingly complicated, and many parties with impaired rights cannot obtain timely relief. Modern civil law begins to gradually demand If you do not act as an infringer, you must also bear the corresponding responsibilities, so you have the basis for the supplementary responsibility. But as mentioned earlier, the emergence of supplementary liability is the result of the expansion of tort liability, which means that the responsible person is burdened with a much heavier burden than before. And this is likely to happen in such a situation that the right holder should fulfill the responsibility of the direct injurer, and the responsible person should bear all the responsibilities, so as to get the relief of his rights more quickly and completely, but let the responsible person They took on a much greater responsibility than their own faults, and they were damaged in disguise. The so-called extremes must be reversed. "Not expanding as a responsibility may lead to excessive restrictions on freedom." 2 Therefore, in order to prevent this from happening, it is necessary to set a series of rules for the application of supplementary responsibilities, limit the supplementary responsibilities in terms of preconditions, commitment methods, and scope of commitment, and prevent excessive expansion of tort liability to balance each the relationship of interests between the parties. This value of supplementary responsibility is the key reason why it must be independent of non-real joint responsibility and responsibility. It is also the most important value function that the author considers to be complementary responsibility.

"We should clearly recognize the balanced role of the legal system in the interests of society and correctly grasp this balance. On the one hand, the victim must be given the necessary adequate protection to compensate for the legal property or personal rights that are damaged; In addition, the defendant's financial compensation must be taken into account." 1 The result of the trade-off is to allow the infringer to assume additional responsibility: on the one hand, the victim is given reasonable if the whereabouts of the direct perpetrator is unclear or incapable of compensation. Relief, on the other hand, imposes restrictions on the rights of victims to prevent their abuse of rights and excessive expansion of tort liability, balancing the interests of various parties and making the whole system more fair and reasonable.

\section{The Applicable Conditions of the Infringement Supplementary Liability}

The liability for infringement supplement is the form of responsibility sharing arising from the 
combination of the positive injuring behavior of the third party and the inaction of the perpetrator. The premise that the responsible person assumes responsibility is that he has committed the infringement, that is, does not act. This kind of inaction does not provide the conditions for the damage caused by the third party when it is carried out. It has certain reasons and the combination of the two acts leads to the damage of others. Therefore, the actor should be liable for compensation. Such inaction is illegal, violates statutory obligations or obligations.

The damage in tort law refers to the loss of the rights or interests of the victim caused by the tort, and the consequences of the damage include the facts of personal injury, the fact of property damage, and the fact of mental damage. The determination of the fact of damage is relatively easy, and in the case of infringement supplementary liability, it is important to determine the scope of the damage facts. In other words, when the responsible person assumes responsibility, is it necessary to compensate the victim for property damage, personal injury or both damages? The author believes that under different types of supplementary liability behaviors, the scope of damage to be determined is also different. For example, in the case of three types of supplementary liability as stipulated in the current Tort Liability Law, when the security obligor and the labor dispatch unit assume additional responsibility, the scope of the damage includes both the property damage and the personal property, because of the two The ability to prevent danger is relatively strong, and the scope of the consequences of damage that requires its responsibility to be exemplified reflects the principle of fairness to a certain extent. Compared with the former two, the scope of damages for the supplementary responsibility of educational institutions should only include personal injury suffered by persons who have no or limited capacity for civil conduct. Because educational institutions such as schools are the main body of public welfare, their responsibilities should be appropriately reduced.

The occurrence of infringement supplementary liability is the result of the combination of the direct infringement of the third party and the inaction of the supplementary responsible person. The direct violation of the third party is the direct cause; the negative inaction of the responsible person is an indirect cause. If the inaction of the responsible person is not supplemented, the consequences of the damage can still occur, but this does not mean that the inaction of the responsible person has nothing to do with the occurrence of the damage. This relationship is reflected in two aspects. First, when the damage occurs, the inaction increases the possibility of the damage to some extent. Second, the inaction causes the damage that might have occurred. The expansion is more than the result of damage that may result from the infringement of the direct infringer. It must be said that in both cases, there is a causal relationship between inaction and the consequences of damage.

\section{Conclusion}

Based on the existing research results, this paper conducts a comprehensive and in-depth theoretical and judicial practice analysis of the infringement supplementary liability, and attempts to put forward relevant suggestions for improvement, in order to continuously deepen the research on the infringement supplementary liability system and the continuous Improve the effect of promotion.

\section{References}

[1] Zhang Xinbao, Tang Qinglin. Operators' safety guarantee obligations to service places. Legal Research, 2003, 2:26.

[2] Bai Junsheng. Research on Supplementary Responsibility of Infringement. Inner Mongolia: Inner Mongolia University, 2010:11.

[3] Cai Junlong. Analysis of the Legal Nature of Supplementary Liability for Tort. Fujian Law, 2009, 3:10.

[4] Yang Lixin. On the supplementary responsibility of tort liability. The law applies, 2009, 6:18.

[5] Huang Long. Research on Civil Supplementary Liability. Journal of Guangxi Police College, 2007, 4: 17-18. 